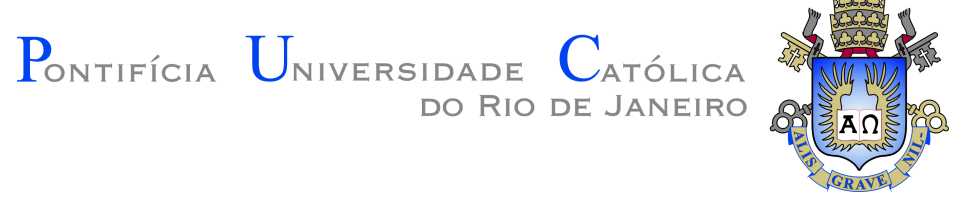

Hanri Neves Pereira Junior

\title{
Matemática e Programação: Uma nova abordagem de ensino
}

Dissertação de Mestrado

Dissertação apresentada como requisito parcial para obtenção do grau de Mestre pelo Programa de Pós-graduação em Matemática, do Departamento de Matemática da PUC-Rio.

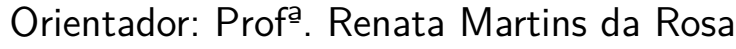




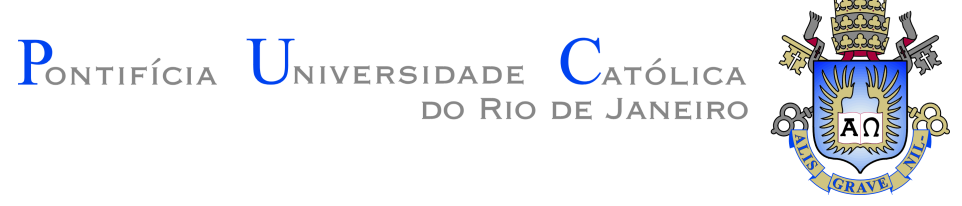

Hanri Neves Pereira Junior

Matemática e Programação: Uma nova
abordagem de ensino

Dissertação apresentada como requisito parcial para obtenção do grau de Mestre pelo Programa de Pós-graduação em Matemática da PUC-Rio. Aprovada pela Comissão Examinadora abaixo:

Profa. Renata Martins da Rosa

Orientador

Departamento de Matemática - PUC-Rio

Prof. Eduardo Barbosa Pinheiro Departamento de Matemática - PUC-Rio

Prof. Wilson Reis de Souza Neto Departamento de Matemática - PUC-Rio

Profạ. Emília Carolina Santana Teixeira Alves

UFF 
Todos os direitos reservados. A reprodução, total ou parcial do trabalho, é proibida sem a autorização da universidade, do autor e do orientador.

\section{Hanri Neves Pereira Junior}

Graduou-se em matemática pela Universidade do Estado do Rio de Janeiro em 2011. Cursou Ciências aturais na Universidade Federal do Rio de Janeiro no ano de 2016, não concluindo o curso. É professor da rede pública e particular de ensino.

Ficha Catalográfica

Pereira Junior, Hanri Neves

Matemática e Programação: Uma nova abordagem de ensino / Hanri Neves Pereira Junior; orientador: Renata Martins da Rosa. - 2021.

$40 \mathrm{f}$ : il. color. ; $30 \mathrm{~cm}$

Dissertação (mestrado) - Pontifícia Universidade Católica do Rio de Janeiro, Departamento de Matemática, 2021.

Inclui bibliografia

1. Matemática - Teses. 2. Ensino de matemática. 3. Pensamento computacional. 4. Programação. I. Rosa, Renata Martins da. II. Pontifícia Universidade Católica do Rio de Janeiro. Departamento de Matemática. III. Título. 


\section{Agradecimentos}

A minha orientadora Professora Renata Martins da Rosa, pelo estimulo, paciência e parceria quando tudo parecia impossível;

A Capes, a SBM e a PUC-Rio, Pelos auxílios concedidos, sem os quais este trabalho não poderia ser realizado;

O presente trabalho foi realizado com apoio da Coordenação de Aperfeiçoamento de Pessoal de Nível Superior - Brasil (CAPES) - Código de Financiamento 001;

Ao professor Wilson pela ajuda e troca de ideias;

Aos meus colegas da PUC-Rio;

Aos professores que participaram da banca examinadora;

A todos os professores e funcionários do departamento pelos ensinamentos e pela ajuda;

A professora Christine pela paciência e perseverança;

Aos meus pais pela educação e carinho;

A todos os amigos e familiares que sempre me incentivaram e me estimularam de alguma forma;

A minha companheira Anna Carolina pelo incentivo e apoio. 


\section{Resumo}

Pereira Junior, Hanri Neves; Rosa, Renata Martins da. Matemática e Programação: Uma nova abordagem de ensino. Rio de Janeiro, 2021. 40p. Dissertação de Mestrado - Departamento de Matemática, Pontifícia Universidade Católica do Rio de Janeiro.

Nas últimas décadas passamos por uma grande (r)evolução tecnológica, portanto, é indispensável que nossa sociedade tenha conhecimentos tecnológicos, dentre esses, o pensamento computacional e a linguagem computacional. Parte desse crescimento tecnológico vem da necessidade de resolução de problemas, muito deles ligados à matemática. No Brasil, temos a BNCC, que propõe relacionar resolução de problemas e pensamento computacional. Portanto esta pesquisa tem como objetivo trazer uma conexão entre essas duas áreas a fim de atender as demandas do professor, que pode precisar de uma ajuda na criação de uma aula envolvendo programação e matemática, e do aluno, que por sua vez precisa estar familiarizado com novas tecnologias que o mercado de trabalho exige. Propomos atividades com o uso de programas com linguagens computacionais a fim de estimular a discussão e inserção do pensamento computacional através da matemática nos currículos escolares. E por fim, este trabalho apresenta os resultados das atividades propostas, com os tópicos a serem considerados no que diz respeito ao PC e a matemática aplicada no ensino básico.

\section{Palavras-chave}

Ensino de matemática; Pensamento computacional; Programação. 


\section{Abstract}

Pereira Junior, Hanri Neves; Rosa, Renata Martins da (Advisor). Mathematics and Programming: A new teaching approach. Rio de Janeiro, 2021. 40p. Dissertação de Mestrado - Departamento de Matemática, Pontifícia Universidade Católica do Rio de Janeiro.

In recent decades we have gone through a great technological (r)evolution, therefore, it is essential that our society has technological knowledge, among these, computational thinking and computational language. Part of this technological growth comes from the need to solve problems, many of them linked to mathematics. In Brazil, we have the BNCC, which proposes to relate problem solving and computational thinking. Therefore, this research aims to bring a connection between these two areas in order to meet the demands of the teacher, who may need help in creating a class involving programming and mathematics, and the student, who in turn needs to be familiar with new technologies that the labor market demands. We propose activities with the use of programs with computational languages in order to stimulate the discussion and insertion of computational thinking through mathematics in school curricula. Finally, this work presents the results of the proposed activities, with topics to be considered with regard to computational thinking and applied mathematics in basic education.

\section{Keywords}

Math teaching; Computational thinking; Programming. 


\section{Sumário}

1 Introdução $\quad 10$

2 Ensino $\quad 12$

2.1 Pensamento Computacional e a Matemática 12

2.2 A Base Nacional Comum Curricular (BNCC) 13

$\begin{array}{lll}2.3 & \text { Interdisciplinaridade e Metodologia } & 15\end{array}$

3 Linguagem e Programação $\quad 16$

$\begin{array}{lll}3.1 & \text { SCRATCH } & 16\end{array}$

$\begin{array}{ll}3.2 \text { Blockly } & 17\end{array}$

$\begin{array}{lll}3.3 & \text { Sonic Pi } & 18\end{array}$

4 Sobre as Atividades Utilizando o Sonic Pi 20

4.1 Um pouco de teoria musical 20

4.2 Definição de Uma Função 22

4.3 Relato da Experiência em Sala de Aula 23

$\begin{array}{ll}4.4 \text { Mais Atividades } & 29\end{array}$

5 Conclusão e Considerações Finais 33

6 Referências Bibliográficas $\quad 39$ 


\section{Lista de figuras}

Figura 3.1 Ao executar o bloco, o gato da três passos e gira $90^{\circ}$ no sentido horário

Figura 3.2 Ao executar o bloco, o gato da três passos e gira $90^{\circ}$ no sentido horário

Figura 3.3 Blockly games

$\begin{array}{ll}\text { Figura 3.4 } & \text { Interface Sonic Pi } \\ \text { Figura 3.5 } & \text { Mozart Requiem in D minor através do Sonic Pi (aces- }\end{array}$

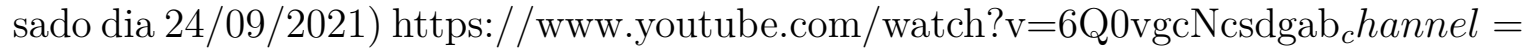
rbn1tube.

Figura 4.1 notas e frequências músicais $\quad 21$

Figura 4.2 Notas musicais e frequência no Sonic Pi 22

Figura 4.3 Relação entre as notas e a reprodução numérica do Sonic $\mathrm{Pi}$

Figura 4.4 Replica do computador Colossus. 24

Figura 4.5 Gráfico da função dada por $\mathrm{f}(\mathrm{x})=-\mathrm{x}^{2}+20 . \quad 27$

Figura 4.6 Registro das notas tocadas pelo Sonic Pi. 28

$\begin{array}{lll}\text { Figura } 4.7 & \text { Gráfico do código } 4.7 & 30\end{array}$

Figura 4.8 Gráfico do código 4.4 31

Figura 4.9 Sequência de Fibonacci 31

$\begin{array}{ll}\text { Figura } 5.1 & 33\end{array}$

Figura $5.2 \quad 34$

Figura $5.3 \quad 34$

Figura $5.4 \quad 35$

Figura $5.5 \quad 35$

$\begin{array}{ll}\text { Figura } 5.6 & 36\end{array}$

$\begin{array}{ll}\text { Figura } 5.7 & 36\end{array}$

Figura $5.8 \quad 36$

$\begin{array}{ll}\text { Figura } 5.9 & 37\end{array}$ 


\section{Lista de Códigos}

Código 4.1: https://www.youtube.com/watch?v=bMbG5C1SSQI (0:00)

Código 4.2: https://www.youtube.com/watch?v=bMbG5C1SSQI (0:16)

Código 4.3: https://www.youtube.com/watch?v=bMbG5C1SSQI (0:31)

Código 4.4: https://www.youtube.com/watch?v=bMbG5C1SSQI (0:45)

Código 4.5: https://www.youtube.com/watch?v=bMbG5C1SSQI (1:07)

Código 4.6: https://www.youtube.com/watch?v=bMbG5C1SSQI (1:17)

Código 4.7: https://www.youtube.com/watch?v=bMbG5C1SSQI (1:27)

Código 4.8: https://www.youtube.com/watch?v=bMbG5C1SSQI (1:42) 


\section{Introdução}

Nas últimas décadas vivemos por uma grande (r)evolução tecnológica, e tendo isso como um fato, é indispensável que nossa sociedade tenha conhecimentos tecnológicos, dentre esses, o pensamento computacional e a linguagem computacional. Países e cidades do mundo começaram a tornar obrigatório o ensino de programação nas escolas, colocando em seus currículos metas para que a crianças do ensino básico desenvolvam habilidades para que resolvam problemas utilizando meios digitais. As novas tecnologias e o aumento exponencial da informação levam a uma nova organização de trabalho (Mercado, L.P.L., 1998).

A principal motivação para desenvolver essa pesquisa foi, ao longo dos anos, perceber que talvez os professores não acompanhem assuntos como linguagens tecnológicas, e isso talvez se deve até o momento a não inclusão de assuntos tecnológicos ao currículo escolar.

$\mathrm{Na}$ tentativa de fugir de aulas tradicionalmente teóricas, há tempos atrás numa escola pública, foi realizado um pequeno experimento com alunos do primeiro ano do ensino médio, que envolvia música, tecnologia e matemática. Utilizando um software que retorna funções com sons e frequência. Pois bem, esse pequeno experimento não deu muito certo, pois a escola em questão não tinha o material mínimo necessário para realizar tal tarefa, e agora retornando a academia me sinto motivado a realizar esse experimento. Sinto que o professor, nesse contexto, precisa inovar e renovar, permitindo o desenvolvimento de ambientes tecnológicos, despertando a curiosidade em novas linguagens e saberes. Portanto, faço deste trabalho uma alternativa para o despertar da curiosidade, a partir de assuntos que permeiam a matemática, a programação e a música.

O processo de aprendizagem de programas e sistemas novos não só para alunos, mas professores e trabalhadores (não necessariamente ligados ao ensino). Sempre temos que aprender novas funções de um celular novo, update de computador, uso de sites de banco, preenchimento de formulários on line. Utilizar o programa chamado Sonic Pi, feito para músicos e programadores, é uma ótima maneira de aprender programação e ao mesmo tempo criar músicas, sons e efeitos sonoros. Assim como qualquer instrumento tem suas 
particularidades e potencialidades que podem ser exploradas, ao utilizar o Sonic Pi, o computador pode ter essa função de um instrumento musical, e é a partir desse novo instrumento musical que proponho a relação entre a música, programação e matemática. Acredito que estimulando a curiosidade dos alunos, é possível ensinar matemática, música e programação. Além disso, relacionar som com matemática pode ajudar a tornar a aula de matemática mais inclusiva.

Como é imprescindível trazer conceitos computacionais para a educação básica, analiso a Base Nacional Comum Curricular (BNCC), que do ensino fundamental ao ensino médio estabelece competências e habilidades matemáticas utilizando as TIC (Tecnologia da Informação e Comunicação). Fazendo com que a computação se torne também uma ferramenta matemática. Podemos dizer então que a BNCC norteia algo relativo à resolução de problemas e programação.

Neste trabalho proponho atividades usando o programa Sonic Pi. Feito algumas das atividades com alunos do ensino médio do Colégio Estadual Coronel Sergio José do Amaral, Situado no bairro de Suruí, no município de Magé - RJ. No capítulo 4 onde é apresentado um relato da experiência. 


\section{Ensino}

\section{1}

\section{Pensamento Computacional e a Matemática}

A primeira definição de pensamento computacional, que atrela um conjunto de habilidades e competências à ciência da computação no qual os estudantes deveriam obter desde os primeiros anos escolares, foi proposta por Wing (2006). Segundo ela, o pensamento computacional é um modo de pensar humano, portanto, podemos considerar o pensamento computacional uma habilidade intelectual básica, como ler, escrever e realizar operações matemáticas.

Num curso de matemática, o aluno desenvolve: construções de algoritmos, interpretação e representação de dados, podemos então de certa maneira, inserir o pensamento computacional na educação básica através da disciplina de matemática e, como veremos a frente, a BNCC garante a inserção.

Os conhecimentos em computação são tão importantes para a vida na sociedade contemporânea quanto os conhecimentos básicos de matemática, filosofia, física, dentre outras, assim como contar, abstrair, pensar, relacionar ou medir. Desta forma, torna-se fundamental tanto no presente quanto no futuro que todos os indivíduos tenham conhecimentos básicos de computação. [BRACKMANN, CHRISTIAN PUHLMANN, 2017].

Existem os chamados "Quatro pilares do pensamento computacional":

- Decomposição: Consiste em pegar um problema e fragmentá-lo e em partes menores que podem ser resolvidas separadamente.

- Reconhecimento de padrões: Observar padrões em cada fragmento.

- Abstração: Focar nos detalhes que ainda não foram vistos.

- Algoritmo: São as instruções, ou regras, que podem ser criadas a fim de resolver o problema.

Tendo em vista todos processos de resolução de problemas matemáticos, temos a modelagem matemática, esta tendência pode ser utilizada como importante recurso nos processos de ensino e de aprendizagem por possibilitar o 
tratamento de conteúdos matemáticos por meio da problematização e modelação de fenômenos reais e sociais pelos estudantes. Devemos fazer com que o método tenha sentido para o aluno e que não seja mais um conteúdo com o qual ele necessite "aprender" apenas para a aprovação. D’Ambrósio (2005) afirma que contextualizar a matemática é essencial para todos, o autor utiliza o exemplo da relação de "Os Elementos" de Euclides com o panorama cultural da Grécia Antiga como argumento para exemplificar o objetivo principal da Matemática, que é a produção de conhecimento e também como comparativo da produção de conhecimento científico, a qual já não ocorre dentro do contexto educacional devido às técnicas de reprodução do conhecimento matemático acumulado historicamente.

De acordo com Burak (1992), o ensino da matemática, na maioria das escolas, com raras exceções, enfatiza em demasia as regras, a memorização para as respostas às questões matemáticas. Observamos desde as séries iniciais que exercícios relativos a um determinado conteúdo são padronizados e repetitivos, sendo utilizados certos artifícios de mnemônica. A prática educativa, no caso, envolve apenas o armazenamento dos fatos na memória.

Não é demais destacar que, também no Ensino Médio, os estudantes devem desenvolver e mobilizar habilidades que servirão para resolver problemas ao longo de sua vida - por isso, as situações propostas devem ter significado real para eles. Nesse sentido, os problemas cotidianos têm papel fundamental na escola para o aprendizado e a aplicação de conceitos matemáticos, considerando que o cotidiano não se refere apenas às atividades do dia a dia dos estudantes, mas também às questões da comunidade mais ampla e do mundo do trabalho (BNCC, 2018). Também se evidencia como a modelagem pode corroborar com as aulas de matemática e favorecer a aprendizagem estabelecendo relações entre o conteúdo aprendido em sala de aula com o contexto social no qual os alunos estão inseridos promovendo assim o Letramento Matemático.

\section{2}

\section{A Base Nacional Comum Curricular (BNCC)}

A BNCC é um documento de caráter normativo que norteia os currículos dos sistemas público e privado do ensino básico no Brasil, conforme diz a Lei de Diretrizes e Bases Da Educação Nacional (LDB, Lei nº 9,934/1996).

No que diz respeito a inserção de tecnologias já no ensino fundamental, na BNCC temos o seguinte trecho: "O Ensino Fundamental deve ter compromisso com o desenvolvimento do letramento matemático, definido como as competências e habilidades de raciocinar, representar, comunicar e argumentar matematicamente, de modo a favorecer o estabelecimento de conjecturas, 
a formulação e a resolução de problemas em uma variedade de contextos, utilizando conceitos, procedimentos, fatos e ferramentas matemáticas.". Levando em consideração que o Pensamento Matemático é do tipo que envolve o raciocínio lógico, e nesse contexto, o pensamento computacional e a modelagem matemática aparecem como uma forma de resolver problemas e ajudar o desenvolvimento do raciocínio lógico, podemos dizer que a computação se torna uma das ferramentas matemáticas, que é parte das competências específicas da BNCC. O ensino de conceitos básicos de computação nas escolas é fundamental, assim como a sua inserção no atual currículo brasileiro por meio de políticas nacionais, possibilitando a formação de cidadãos capazes de viverem em uma sociedade globalizada. (FIORELLI SILVA et al. 2020).

Já no ensino médio, a BNCC propõe o uso de calculadoras e planilhas digitais. Fala-se muito da importância do recurso a tecnologias digitais para dar continuidade ao pensamento computacional visto no ensino fundamental. O processo de investigação, de construção de modelos matemáticos e de resolução de problemas é uma habilidade sempre tocada. A competência 5.2 é muito clara também quando diz: "A importância do recurso a tecnologias digitais tanto para a investigação matemática como para dar continuidade ao desenvolvimento do pensamento computacional". Percebe-se que não há um consenso em relação a metodologias e nem expectativas para atender as demandas dos profissionais da educação, uma das propostas possíveis seria talvez pesquisar sobre a possibilidade de criar atividades onde seja possível universalizar o pensamento computacional, levanto atividades, como a computação desplugada, onde não exista talvez dispositivos eletrônicos. A computação desplugada é uma técnica que tem por intuito ensinar os fundamentos da ciência da computação de forma simples e lúdica sem o uso de computadores, que ainda pode ser aplicado a qualquer pessoa de diferentes idades independente de recursos com hardware e/ou software, agindo de maneira eficaz e eficiente, (MACHADO et al., 2010).

Existe todo um capítulo no ensino médio da BNCC voltado para as tecnologias digitais: "pensamento computacional envolve as capacidades de compreender, analisar, definir, modelar, resolver, comparar e automatizar problemas e suas soluções, de forma metódica e sistemática, por meio do desenvolvimento de algoritmos".

Quando se trata das competências e habilidades pautadas pela BNCC, sempre há discussão das resoluções de problemas, no que tange a identificação de aspectos consensuais ou não dos problemas investigados, além das propostas de interpretar, construir modelos e resolver problemas dos mais diversos contextos construindo sempre argumentos sólidos. Estamos falando, mesmo 
que em outras palavras, sobre a modelagem matemática.

\section{3}

\section{Interdisciplinaridade e Metodologia}

O uso de tecnologia por si só não é o suficiente, é preciso desenvolver o pensamento matemático através dela. De acordo com o dicionário Houaiss da língua portuguesa, a interdisciplinaridade é "algo que estabelece relação entre duas ou mais disciplinas ou ramos de conhecimento" ou "o que é comum em duas ou mais disciplinas". Utilizaremos a matemática, o pensamento computacional e a música de forma interdisciplinar, de modo que desperte a curiosidade no aluno.

O foco deste trabalho está na forma de apresentar essa interdisciplinaridade, analisando sob a ótica de uma pedagogia que encara a aprendizagem como um processo de construção do conhecimento. A BNCC quando define as competências gerais diz: "Exercitar a curiosidade intelectual e recorrer a abordagem própria da ciência, incluindo a investigação, a reflexão, a analise crítica, a imaginação e a criatividade, para investigar causas, elaborar e testar hipóteses, formular e resolver problemas e criar soluções (inclusive tecnológicas) com base no conhecimento das diferentes áreas". E a partir da construção de uma atividade experimental, tátil e com conteúdos interdisciplinares, podemos conseguir atrair a atenção e despertar a curiosidade do aluno. Programas interativos vão além do entretenimento, são ótimas ferramentas de ensinoaprendizagem.

A teoria dos Registros de Representação Semiótica na matemática, desenvolvida por Duval, diz que é necessário mobilizar, simultaneamente, o maior número de representações semióticas de um mesmo conceito para o desenvolvimento do pensamento matemático. Duval (2003) agrupa as representações nos seguintes grupos: linguagem natural, sistemas de escrita, figuras geométricas e gráficos. Neste trabalho, apresento experimentos na tentativa de acrescentar a representação sonora a esses grupos. 


\section{3 \\ Linguagem e Programação}

Assim que as primeiras linguagens modernas de programação começaram a surgir (década de 1940), tínhamos apenas códigos matemáticos, com o passar dos anos foram surgindo dezenas de linguagens, do ENIAC Coding System em 1943, até a Kotlin em 2016. E continuam surgindo novas linguagens. Algumas mais fáceis outras complexas, com uma determinada linguagem para o um tipo específico de problema, ou seja, a escolha da linguagem está diretamente atrelada a um tipo de problema que queremos resolver.

\section{1}

\section{SCRATCH}

Na educação básica muito se usa o SCRATCH, uma linguagem de programação visual, que são recursos que buscam apoiar a construção e a interpretação de programas de computador, desenvolvida no Massachusetts Institute Of Technology (MIT). No SCRATCH não é necessário criar ou digitar nenhum comando complicado, você apenas conecta blocos gráficos para criar programas.

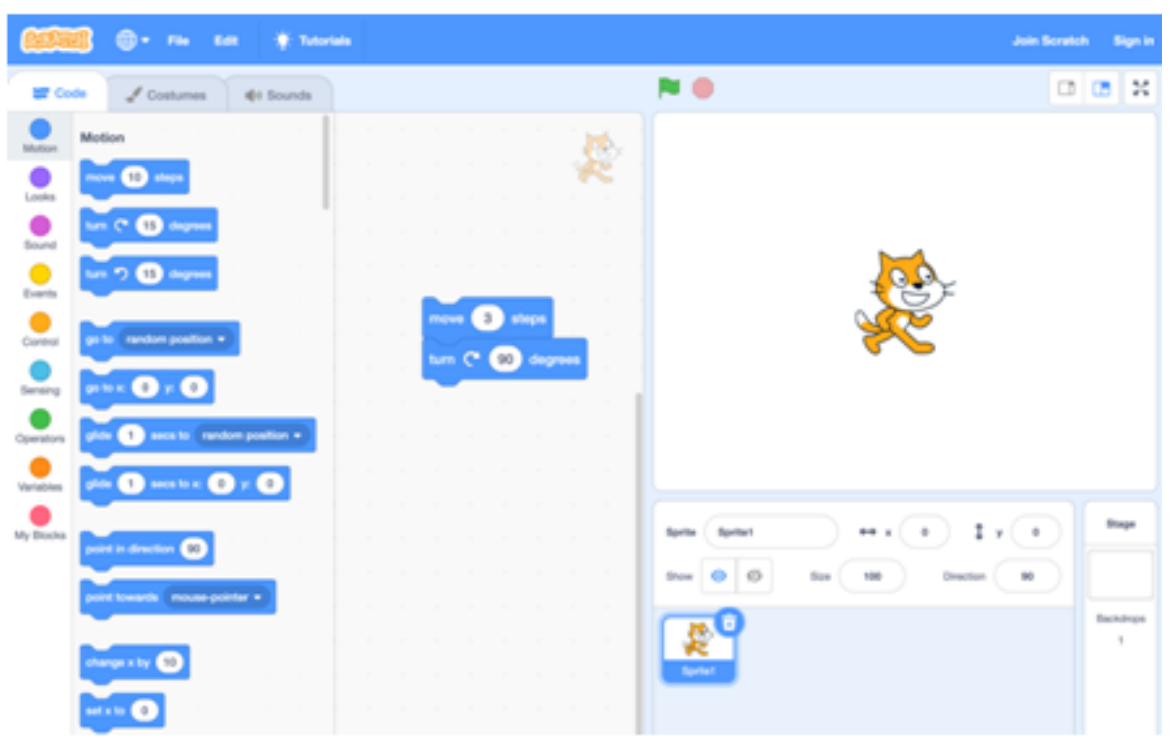

Figura 3.1: Ao executar o bloco, o gato da três passos e gira $90^{\circ}$ no sentido horário 


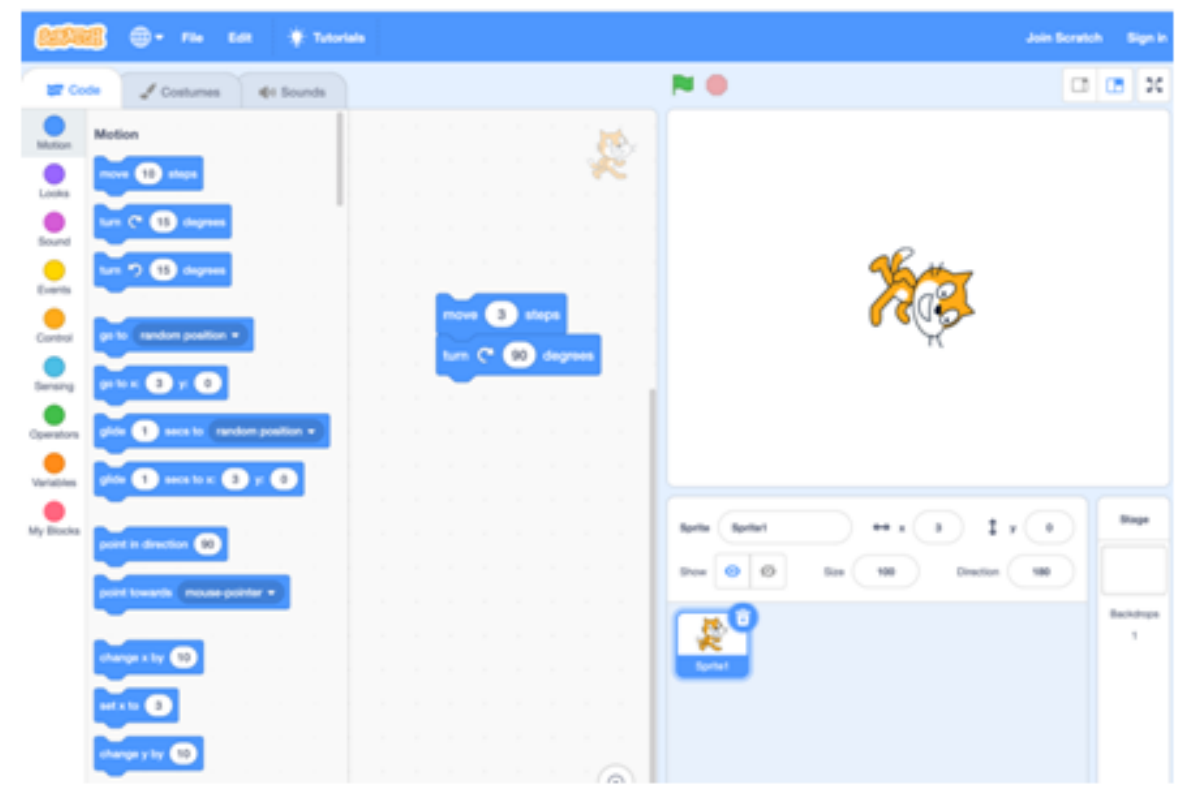

Figura 3.2: Ao executar o bloco, o gato da três passos e gira $90^{\circ}$ no sentido horário

O gato (figura 3.1 e 3.2) é chamado de script, e esses scripts obedecem a um conjunto de instruções que o usuário atribui. E assim, como podemos move-los, podemos também atribuir outras funções, como repetir frases, trocar roupas, realizar operações matemáticas e outras.

\section{2}

\section{Blockly}

Blockly é uma biblioteca que adiciona um editor de código visual a aplicativos da web e móveis. O editor Blockly usa blocos gráficos interligados para representar conceitos de código como variáveis, expressões lógicas, loops e muito mais. Ele permite que os usuários apliquem os princípios de programação sem se preocupar com a sintaxe ou a intimidação de um cursor piscando na linha de comando. Utilizam elementos gráficos como blocos encaixáveis ou fluxogramas de componentes conectáveis para representar instruções de linguagens de programação. Estas metáforas visuais buscam aproximar conceitos de linguagens de programação a atividades familiares aos usuários. Reduzem, dessa maneira, a carga cognitiva sobre os alunos, contribuindo para a construção de projetos significativos (PASTERNAK, 2009).

Na figura 3.3, temos o Blockly games, que consistem em resolver pequenos problemas, juntando os blocos e assim fazendo com que o nosso script se mova na linha vermelha ate o ponto de chegada. 


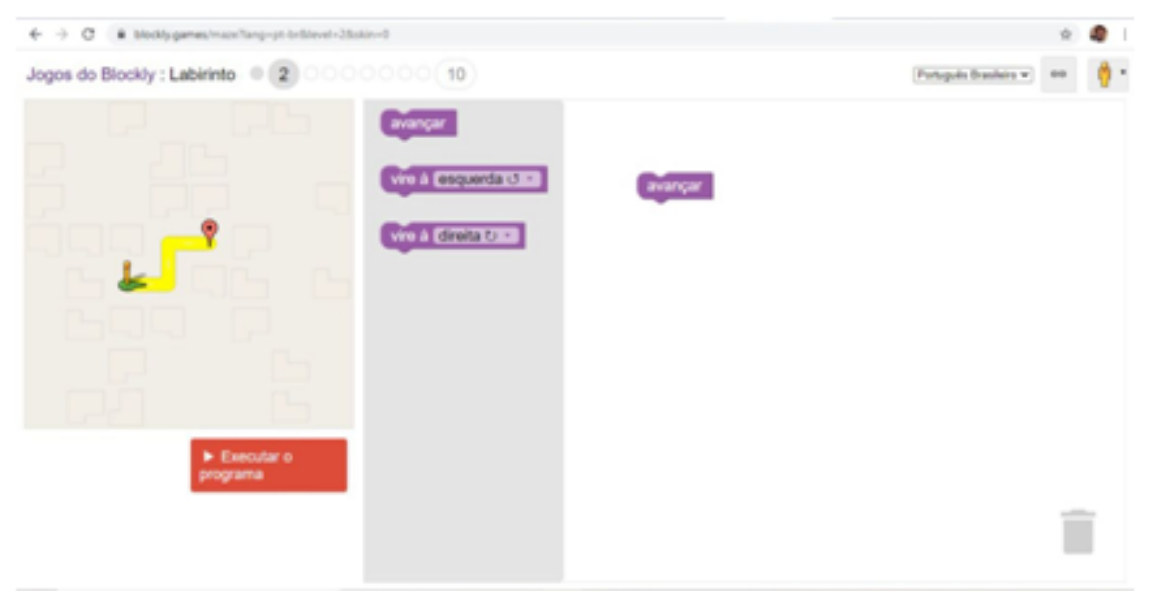

Figura 3.3: Blockly games

\section{3}

\section{Sonic Pi}

O Sonic Pi é um programa livre e gratuito, desenvolvido para promover a programação e a música. O programa foi criado por Sam Aaron, pesquisador e professor da University of Cambrige em colaboração com a fundação RaspberryPi. Sonic Pi é uma ótima forma de introduzir noções de programação e música. A estrutura do Sonic Pi é baseada na linguagem Ruby, desenvolvida no Japão em 1995, por Yukihiro "Matz"Matsumoto, para ser usada como linguagem de script. Sua estrutura utiliza a plataforma de código livre de processamento sonoro o sintetizador Supercollider12, que também pode ser usado para performances ao vivo. Sua estrutura permite que o usuário mude os parâmetros e execute as mudanças sem a necessidade de interrupção do processamento sonoro.

A entrada de dados é feita através de linhas de códigos que quando executados podem representar uma nota musical, um sintetizador ou algum tipo de efeito sonoro. Abaixo temos a imagem da interface do Sonic Pi:

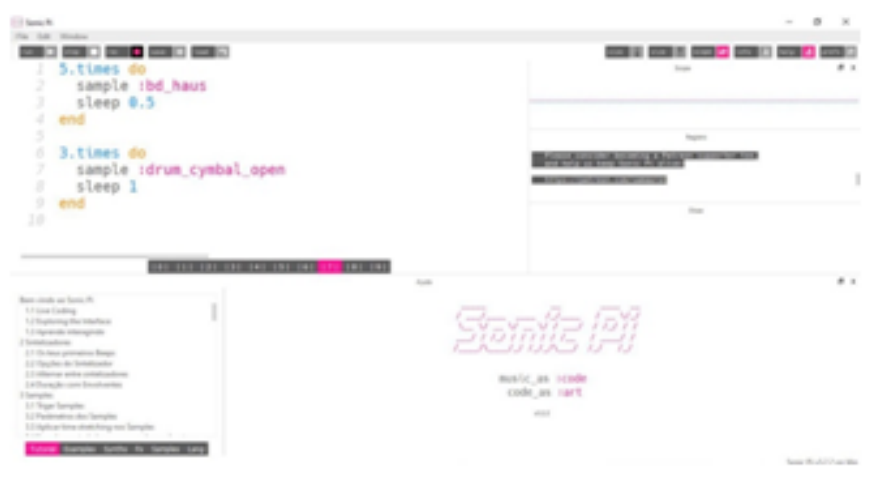

Figura 3.4: Interface Sonic Pi

É um ambiente de codificação ao vivo, baseado originalmente projetado 
para dar suporte a aulas de computação e música nas escolas, feito para uma nova geração de músicos, simples de aprender, poderoso o suficiente para apresentações ao vivo e gratuito para download. Ele é uma ótima maneira de aprender programação e ao mesmo tempo criar música. Sua simplicidade o torna um programa inteligente, eficiente e fácil de usar. É voltado tanto para jovens quanto para músicos experientes, curiosos, experts ou interessados em criar música através de códigos.

Precisamos de basicamente dos comandos:

- Play: O comando que emite o som;

- Sleep: O tempo que você irá esperar ate emitir o próximo som;

- Sample: É uma biblioteca onde existem uma lista de sons, inclusive instrumentos musicais. Existe também a possibilidade de você gravar um som e alimentar essa biblioteca.

Se usarmos o play seguido de um número, o programa produz um beep. Os números estão relaciona notas de um piano de acordo com o protocolo MIDI (Musical Instrument Digital Interface). ${ }^{1}$

Na figura 3.3, por exemplo, é tocado por 5 vezes num intervalo de meio segundo uma marcação e bateria, e logo depois toca por 3 vezes num intervalo de 1 segundo um dos pratos da bateria.

Temos criações mais complexas como a reprodução de Morzart Requiem in $\mathrm{D}$ minor.

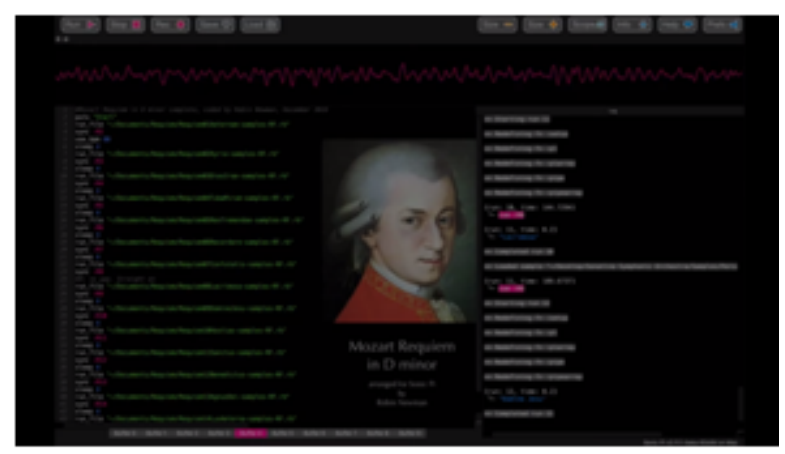

Figura 3.5: Mozart Requiem in D minor através do Sonic Pi (acessado dia

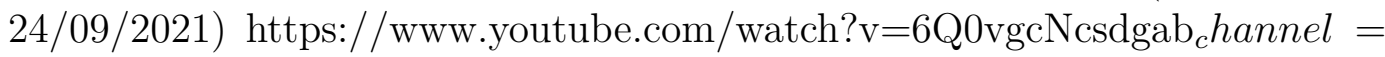
rbn1tube.

\footnotetext{
${ }^{1}$ MIDI é um padrão de interconexão física criado em 1992 por um grupo de fabricantes de sintetizadores japoneses e americanos para facilitar a comunicação entre instrumentos musicais eletrônicos, computadores e dispositivos relacionados.
} 


\section{4}

\section{Sobre as Atividades Utilizando o Sonic Pi}

\section{1}

\section{Um pouco de teoria musical}

De acordo com Martineau (MARTINEAU, 2014), quando a música se une à linguagem, o que é falado torna-se canção, elevando as intenções e pedindo que escutemos mais profundamente, tornando sagrado o que é profano. A música conforta a alma.

Podemos citar como as principais partes que constituem a música são: Melodia (combinação sucessiva de sons), Harmonia (combinação simultânea de sons), Contraponto (conjunto de melodias dispostas em ordem simultâneas - algumas vezes considerada como uma técnica e não como parte da música) e Ritmo (Cadencia obedecendo a combinação de sons com periódicas repetições). Uma vibração põe em movimento ondas sonoras que propagam para todas as direções, e essas ondas geram uma sensação nos ouvidos chamada de som (BROWN, 2015).

As principais características do som são:

- Altura - Determinada pela frequência das vibrações, quanto maior a frequência, mais agudo é o som;

- Duração - é a extensão do som, determinada pelo tempo de emissão da frequência;

- Intensidade - é a amplitude das ondas, determinada pelo volume, ou força da vibração;

- Timbre - é a combinação de vibrações. É a característica do som que cada instrumento ou voz reproduz, derivados dos sons harmônicos que acompanham o som principal.

As notas musicais são sons com frequências determinadas, de tal forma que existe uma relação matemática exata entre elas: 


\begin{tabular}{|c|c|}
\hline Notas & Frequência $(\mathrm{Hz})$ \\
\hline dó & 264 \\
\hline ré & 297 \\
\hline mi & 330 \\
\hline fá & 352 \\
\hline sol & 396 \\
\hline lá & 440 \\
\hline si & 495 \\
\hline dó & 528 \\
\hline
\end{tabular}

Figura 4.1: notas e frequências músicais

A escala musical é uma sucessão de ascendentes ou descendentes de notas musicais diferentes e consecutivas. As oitavas - são intervalos, ou seja, distâncias entre duas notas - são divididas igualmente em doze notas, a escala é uma série de notas selecionadas dentre essas doze notas. Embora sejam inúmeros sons empregados na música, vale ressaltar que a escala é a base de qualquer música, daí a correlação entre a matemática e a música ficam mais evidentes. Abaixo temos as definições das escalas chamadas Natural e Cromática:

- Natural: Também chamada de Diatônica, é aquela que em uma oitava tem as notas Dó, Ré, Mi, Fá, Sol, Lá, Si, Dó, completando o ciclo de oito notas, onde o último Dó (Dó agudo) tem o dobro da frequência do primeiro Dó;

- Cromática ou Temperada: É a composta pelo meio tom entre cada nota, ou seja, Dó, Dó \#, Ré, Ré \#, Mi, Fá, Fá \#, Sol, Sol \#, Lá, Lá \#, Si e Dó.

O Semi Tom ou o Meio Tom é o menor intervalo adotado entre duas notas - no sistema temperado - sendo (\#) o sustenido, que significa meio tom acima, e o bemol (b),que significa meio tom abaixo. O sistema musical ocidental geralmente utiliza uma seleção semitonal dos sons existentes. E o sistema temperado iguala os semi tons em partes perfeitamente iguais, ou seja, por exemplo Dó\#=Ré b. Algumas culturas orientais utilizam em seu sistema musical frações menores que um semi tom (um quarto de tom, um oitavo de tom, etc.).

Embora esses monossilábicos (Dó, Ré, Mi, Fá, Sol, Lá, Si) sejam predominantemente usados em línguas latinas, eles correspondem a sete letras usadas em inglês, alemão, grego, etc.

- C, D, E, F, G, A e H em alemão.

- C, D, E, F, G, A e B em inglês.

No Sonic Pi, usando play seguido de um número inteiro podemos reproduzir sons da escala cromática. Por exemplo: 


\begin{tabular}{|c|c|c|c|c|c|c|c|c|c|c|c|}
\hline Dó & $\begin{array}{c}\text { Dó } \\
\#\end{array}$ & $\operatorname{Re}$ & $\begin{array}{c}\operatorname{Re} \\
\#\end{array}$ & Mi & Fá & $\begin{array}{c}\text { Fá } \\
\#\end{array}$ & Sol & $\begin{array}{c}\text { Sol } \\
\#\end{array}$ & Lá & $\begin{array}{c}\text { Lá } \\
\#\end{array}$ & $\mathrm{Si}$ \\
\hline 60 & 61 & 62 & 63 & 64 & 65 & 66 & 67 & 68 & 69 & 70 & 71 \\
\hline
\end{tabular}

Figura 4.2: Notas musicais e frequência no Sonic Pi

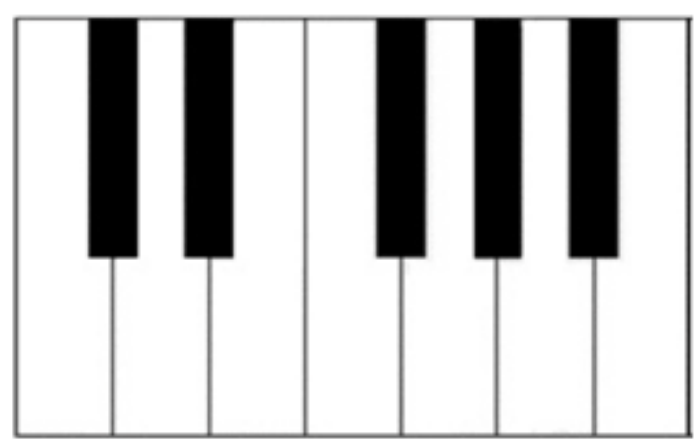

Figura 4.3: Relação entre as notas e a reprodução numérica do Sonic Pi

A relação entre música e matemática tem sido estudada desde a Antiguidade. Na cultura ocidental, os primeiros registros desta relação surgem na Grécia no século IV a. C. Na escola Pitagórica foi feito um experimento relacionando frações de números inteiros e intervalos musicais (EVES, 2014).

Além disso, a relação visual da representação gráfica da música (partitura) com gráficos da matemática pode motivar professores e alunos o uso do Sonic Pi em sala de aula.

Coloquei um vídeo no Youtube onde é possível ouvir os códigos gerados

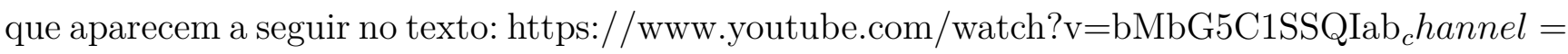
HanriJunior

\section{2}

\section{Definição de Uma Função}

Uma função real, f, é uma relação que, a cada número x de um subconjunto $D$ dos números reais, associa um único número real, denotado por $f(x)$. O conjunto $D$ é chamado o domínio de $f$ e o conjunto dos números reais que estão associados por $f$ a algum número de $\mathrm{D}$ é chamado o conjunto imagem (ou, simplesmente, a imagem) de $f$. O gráfico de uma função $f$ é o subconjunto do plano cartesiano $\left\{(x, y) \in \mathbb{R}^{2} \mid x \in D \Lambda y=f(x)\right\}$ 


\section{3 \\ Relato da Experiência em Sala de Aula}

Fiz a atividade no Colégio Estadual Coronel Sergio José do Amaral, Situado no bairro de Suruí, no município de Magé - RJ. Suruí é um bairro tradicionalmente pesqueiro à beira da baía de Guanabara. Um lugar de classe média baixa a baixa.

De forma facultativa, chamei os alunos dos primeiros anos do ensino médio. Por conta da COVID-19, tive que limitar a quantidade de alunos a no máximo $30 \%$, por isso tive um total de 23 alunos, todos do primeiro ano do ensino médio.

Comecei acolhendo a todos no auditório da escola, e logo em seguida, fiz as seguintes perguntas: Quem já ouviu falar em programação? E música? E matemática? Alguns levantaram as mãos, porém uma minoria. A partir daquele momento de descontração disse que não estava mais como professor e sim como aluno.

Inicialmente falei um pouco sobre música, disse sobre a relação entre a música e matemática. Falei primeiro sobre os compassos musicais, binário, ternário e quaternário, e com o projeto aberto, toquei músicas que seguiam respectivamente esses compassos, e fui visualmente testando a percepção musical dos alunos tocando músicas pelo YouTube. Logo depois falei sobre as notas musicais e sobre as oitavas, em que basicamente são as distancias entre as mesmas notas em tons diferentes e subsequentes. Neste momento vale ressaltar a atenção daqueles que pareciam não saber nada sobre teoria musical. No gancho da teoria musical, aproveitei pra falar que o som nada mais é que uma onda que viaja através do ar, ou seja, são frequências sonoras, onde os sons mais agudos são frequências maiores e sons mais graves, são frequências menores. E que o volume do som na verdade é a amplitude dessas ondas.

Indo para a programação, comentei sobre a história dos computadores, citando Alan Turing, um matemático inglês que influenciou de forma altamente significativa o desenvolvimento da ciência da programação, formalizando o conceito de algoritmo, não pude deixar de comentar sobre o filme "O Jogo da Imitação" que foi baseado em sua vida, e como ele ajudou a interceptar e descriptografar mensagens entre os nazistas no contexto da segunda guerra mundial. Mostrei aos alunos o "Colossus", o computador construído em 1943 através da equipe conhecida como Estação X, liderada por Alan Turing. 


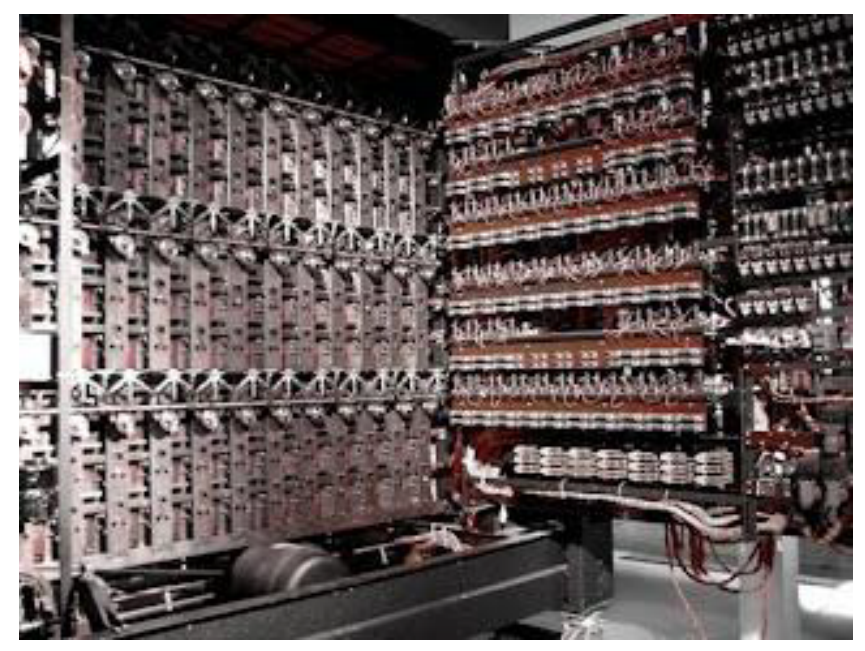

Figura 4.4: Replica do computador Colossus.

Continuando a falar sobre programação, fiz um exemplo do que seria escrever um código sobre nosso dia, começando ao acordar. Fiz as seguintes perguntas:

- Quando acordamos, qual é a primeira coisa que fazemos?

Alguns alunos responderam da seguinte forma:

"Ué! Levantamos"

Outros responderam: "Abrimos o olho"

Depois dessas respostas, fiz outra pergunta: "E depois, o que fazemos?"

As respostas foram:

"Escovamos os dentes", "Tomamos banho", "Colocamos o pé fora da cama" e outras respostas bastante inusitadas.

A partir daí, disse que um bom programa está na riqueza dos detalhes, e quanto mais detalhes, mais "real" e melhor fica o nosso programa. Assim que fiz essa explicação, me fizeram a seguinte pergunta: "E onde fica a matemática nisso aî?"

Disse que nesse caso a matemática fica em como faremos o programa tomar algumas decisões, pra isso usamos a lógica.

A partir dessa breve apresentação sobre programação, comentei sobre as diferentes linguagens de programação, e até no celular algumas dessas linguagens estão presentes. Falei sobre a linguagem Ruby e enfim apresentei o Sonic Pi e sua interface e como através da programação podemos fazer música e basta sabermos dominar a linguagem.

Assim que apresentei a interface do programa, eu falei sobre o básico que eles precisam saber, ou seja, falei sobre os que eu julgo como os três principais códigos, que é o play, o código que "toca" o som, o sleep, que é o tempo 
(em segundos) de pausa entre uma nota e outra, e o sample, que são sons pré-gravados no programa.

Comecei com o play 100 e o play 50 para eles terem uma comparação de números e sons mais agudos e mais graves, onde quanto maior o número, mais agudo é o som. Depois, pra testar a percepção dos alunos, desliguei o projetor e fiz uma brincadeira com eles, e tomando como base o play 60, toquei notas aleatórias e pedi pra que dissessem se era um som mais agudo ou um som mais grave. Liguei o projetor e escrevi o seguinte código:

Código 4.1

20.times do

Play 70

Sleep 0.5

end

Pedi para que eles tentassem me dizer o que iria acontecer. A maioria dos alunos disse que não faziam ideia, porém alguns alunos responderam que o programa tocaria uma nota 20 vezes num intervalo de $0.5 \mathrm{~s}$, disse que acertaram e enfim rodei o programa.

Apesar de rodar um código simples, mostrei pra eles que existem códigos complexos e músicas bem detalhadas que foram programadas no Sonic Pi. Mostrei a eles através do YouTube alguns exemplos de pessoas que fizeram músicas mais detalhadas e reproduziram inclusive músicas eruditas, como a reprodução de Morzart Requiem in D minor, na figura 3.4. Mostrei também algumas bandas reproduzidas no Sonic Pi.

Como eu disse a eles, podemos programar quase tudo, e como o Sonic Pi reproduz em forma de som, podemos então "escutar" matemática.

Comecei fazendo um breve resumo sobre funções até que cheguei na função afim, relembrei o gráfico dessa função no plano cartesiano e a forma geral da expressão da função sendo $f(x)=a x+b$. Perguntei se era possível "tocar" essa função no Sonic Pi. Eles disseram que sim, pois como eu havia dito, "podemos programar quase tudo". Mas prevendo que eles responderiam isso, perguntei se a imagem que seria tocada é a mesma imagem da $f$. Todos disseram que sim, daí fiz outra indagação, o Sonic Pi consegue interpretar números negativos? Reparei que alguns ficaram confusos e fiz a pergunta: "qual será então a imagem de $f$ no Sonic Pi?". Muitos não souberam responder, mas alguns de um modo geral disseram que a imagem será apenas positiva. 
Então disse que se eu reproduzir uma função no Sonic Pi, a imagem deverá ser de números positivos, e pra isso, preciso saber que domínio colocar. Comecei então com a função dada por $f(x)=x$ e como podemos reproduzir essa função, utilizo qualquer domínio ou só domínios positivos? Construí então o seguinte código:

Código 4.2

$$
\begin{aligned}
& \begin{array}{l}
n=10 \\
x=50
\end{array} \\
& \text { n.times do } \\
& \text { play } \mathrm{x} \\
& \text { sleep } 1 \\
& \quad x=x+1 \\
& \text { end }
\end{aligned}
$$

Perguntei o que aconteceria quando eu desse o play. Alguns não sabiam, outros disseram que o "som ia aumentar" e uma pequena parte da turma disse que o som aumentaria de um em um. A partir dessas respostas, qual seria o domínio e a imagem dessa função? Bem quando toquei a função muitos ouviram a função e a partir dessa percepção auditiva conseguiram perceber que a função teria 10 números no domínio e 10 números na imagem. Respondi que o domínio é igual a imagem que, de um em um, vai de 50 a 59, começando no 50 e terminando no 59 .

Código 4.3

$$
\begin{aligned}
& \begin{array}{l}
n=10 \\
x=5
\end{array} \\
& \begin{array}{l}
\text { n.times } \quad d o \\
\text { play } 2^{*} x+1
\end{array} \\
& \quad \text { sleep } \quad 1 \\
& \quad x=x+1 \\
& \text { end }
\end{aligned}
$$

Rodei o código e perguntei se nesse caso a imagem seria igual ao domínio. Eles perceberam que não, foram observando o que eu escrevia na interface, pois estava com o projetor quase todo o tempo ligado. 
Perguntei sobre o gráfico da função quadrática e se eles lembram do que eu havia dito sobre funções. Desliguei o projetor e rodei o seguinte código:

Código 4.4

$$
\begin{aligned}
& n=36 \\
& a=1 \\
& b=-20 \\
& c=0 \\
& k=1 \\
& \text { n.times do } \\
& \text { play }-\left(a^{*} k^{*} k+b^{*} k\right) \\
& \text { sleep } \quad 0.5 \\
& k=k+0.5
\end{aligned}
$$

end

Pedi para que eles, a partir do som "tocado", comentassem sobre qual função eu estava rodando. Quase todos perceberam que era uma função quadrática. Assim que liguei o projetor pedi pra que eles reconhecessem que função é essa. Se daria pra identificar ao menos o coeficiente principal, $a$, da função quadrática e se $a$ é positivo ou negativo. Alterei o sleep de 0.5 para um, assim a função ficava mais nítida. Desenhei o gráfico da função dada por $f(x)=-x^{2}+20 x$.

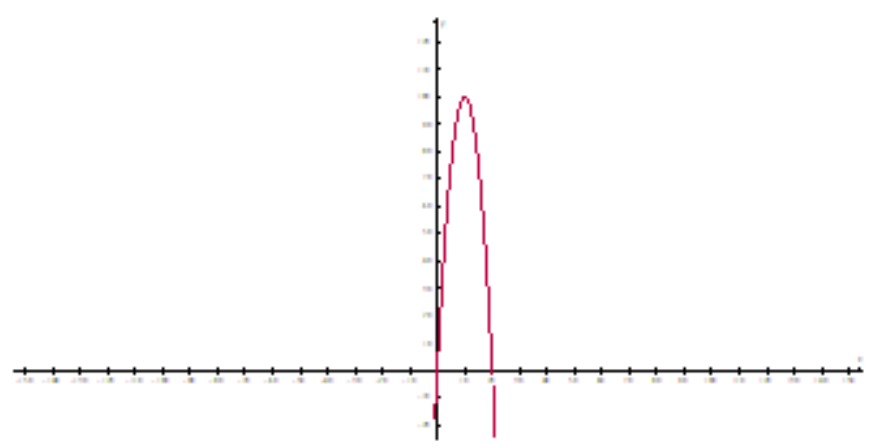

Figura 4.5: Gráfico da função dada por $\mathrm{f}(\mathrm{x})=-\mathrm{x}^{2}+20$.

Perguntei se era possível fazer uma relação entre o gráfico e o som tocado. Alguns não souberam responder e então mostrei o registro do programa, onde se tem as notas tocadas. Veja figura a seguir: 


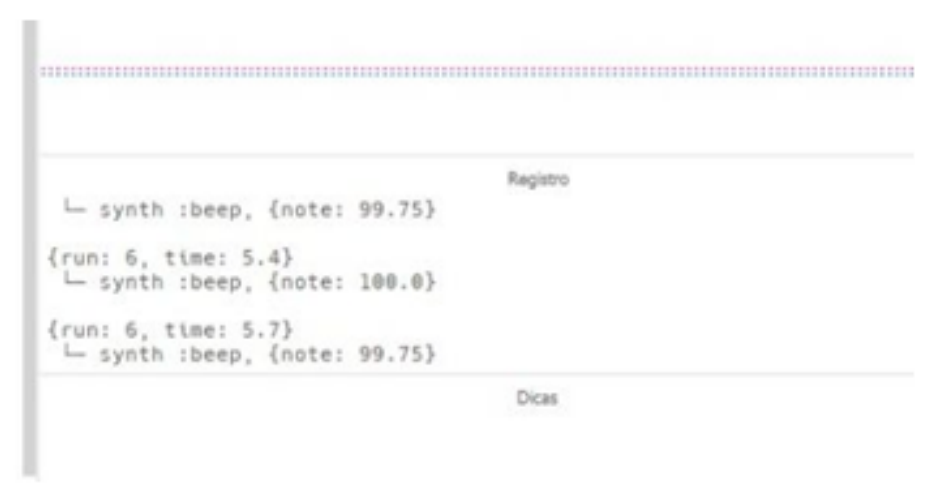

Figura 4.6: Registro das notas tocadas pelo Sonic Pi.

Pedi pra que percebessem como a nota sobe até o 100 e depois desce, e simultaneamente mostrei o gráfico e pedi pra que percebessem que acontece a mesma coisa. Com o tempo quase se esgotando, finalizei rodando mais uma função quadrática, porem essa, com o coeficiente $a>0$. Segue o código:

Código 4.5

$$
\begin{aligned}
& n=20 \\
& a=0.6 \\
& b=-5 \\
& c=100 \\
& k=0 \\
& \text { n.times do } \\
& \text { play }\left(a^{*} k^{*} k+b^{*} k+c\right) \\
& \text { sleep } \quad 0.3 \\
& k=k+0.5
\end{aligned}
$$

Assim que rodei, eles perceberam que se tratava de uma função quadrática de concavidade para cima.

Alguns pediram pra mexer no meu computado e alterar alguns parâmetros de alguns códigos, não hesitei e deixei por alguns minutos, usarem o programa e alterarem alguns parâmetros.

Finalizei a tarefa agradecendo e entregando um formulário para que eles preenchessem com sinceridade (as conclusões serão apresentadas no capítulo 
final deste trabalho). Assim que me entregaram os formulários, liberei para ir embora. Alguns ficaram e me perguntaram como fazia para baixar o programa e se existem outros parecidos. Falei do SCRATCH, Python e Blockly, para os interessados. Disse que existem vários tutoriais no YouTube sobre programação, mas que quase não existem tutoriais sobre o Sonic Pi especificamente, daí me recomendaram fazer um canal, pois de acordo com eles "é um negócio muito legal".

\section{4}

\section{Mais Atividades}

Sugerimos a seguir três exercícios que podem dar continuidade a aula ou complementar as atividades mencionadas acima.

Exercício 1: Tocar o código abaixo e ver é reconhecível.

$\begin{array}{lr}\text { play } & 60 \\ \text { sleep } & 0.5 \\ \text { play } & 60 \\ \text { sleep } & 0.5 \\ \text { play } & 60 \\ \text { sleep } & 1 \\ \text { play } & 62 \\ \text { sleep } & 1 \\ \text { play } & 60 \\ \text { sleep } & 1 \\ \text { play } & 65 \\ \text { sleep } & 1 \\ \text { play } & 64\end{array}$

Exercício 2: Para $\mathrm{x}$ inteiro de 1 até 10, tocar y, sendo que $y=10 x$. Em seguida, tocar na ordem contrária usando também a equação de uma reta. Solução: 
$x=1$

10.times do

$\operatorname{play} 10^{*} x$

sleep 0.5

$x=x+1$

end

10.times do

play $-10 * x+200$

sleep 0.5

$x=x+1$

end

Comparar gráficos e sons desse exercício com os do exercício com parábola do relato.

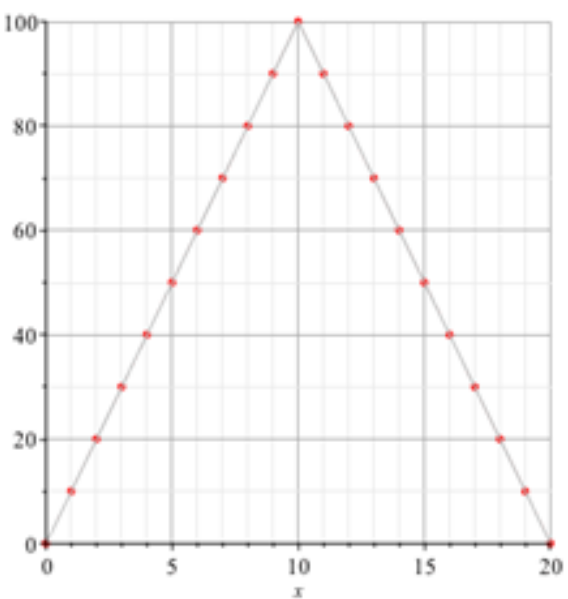

Figura 4.7: Gráfico do código 4.7 


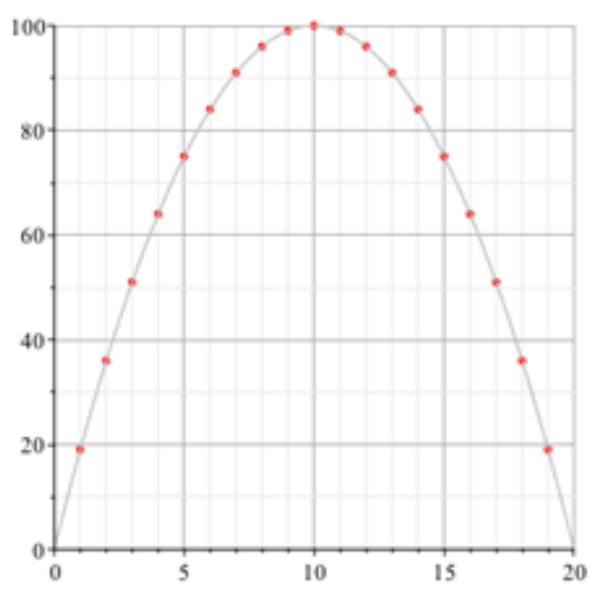

Figura 4.8: Gráfico do código 4.4

Exercício 3: Tocar uma parte da sequencia de Fibonacci.

\begin{tabular}{|c|c|c|c|c|c|c|c|c|c|c|}
\hline 1 & 1 & 2 & 3 & 5 & 8 & 13 & 21 & 34 & 55 & $\cdots$ \\
\hline 1 & 1 & $1+1=2$ & & & & & & & & \\
\hline & 1 & 2 & $1+2=3$ & & & & & & & \\
\hline & & 2 & 3 & $2+3=5$ & & & & & & \\
\hline & & & 3 & 5 & $3+5=8$ & & & & & \\
\hline & & & & 5 & 8 & $5+8=13$ & & & & \\
\hline & & & & & 8 & 13 & $8+13=21$ & & & \\
\hline & & & & & & 13 & 21 & $13+21=34$ & & \\
\hline & & & & & & & 21 & 34 & $21+35=55$ & \\
\hline & & & & & & & & & & $\cdots$ \\
\hline
\end{tabular}

\begin{tabular}{|c|c|c|c|c|c|c|c|c|c|c|}
\hline 1 & 1 & 2 & 3 & 5 & 8 & 13 & 21 & 34 & 55 & $\cdots$ \\
\hline $\mathrm{a}$ & $\mathrm{b}$ & $\mathrm{c}=\mathrm{a}+\mathrm{b}$ & & & & & & & & \\
\hline & $\mathrm{a}$ & $\mathrm{b}$ & $\mathrm{c}=\mathrm{a}+\mathrm{b}$ & & & & & & & \\
\hline & & $\mathrm{a}$ & $\mathrm{b}$ & $\mathrm{c}=\mathrm{a}+\mathrm{b}$ & & & & & & \\
\hline & & & $\mathrm{a}$ & $\mathrm{b}$ & $\mathrm{c}=\mathrm{a}+\mathrm{b}$ & & & & & \\
\hline & & & & $\mathrm{a}$ & $\mathrm{b}$ & $\mathrm{c}=\mathrm{a}+\mathrm{b}$ & & & & \\
\hline & & & & & $\mathrm{a}$ & $\mathrm{b}$ & $\mathrm{c}=\mathrm{a}+\mathrm{b}$ & & & \\
\hline & & & & & & $\mathrm{a}$ & $\mathrm{b}$ & $\mathrm{c}=\mathrm{a}+\mathrm{b}$ & & \\
\hline & & & & & & & $\mathrm{a}$ & $\mathrm{b}$ & $\mathrm{c}=\mathrm{a}+\mathrm{b}$ & \\
\hline & & & & & & & & $\mathrm{a}$ & $\mathrm{b}$ & $\mathrm{c}=\mathrm{a}+\mathrm{b}$ \\
\hline & & & & & & & & & & $\cdots$ \\
\hline
\end{tabular}

Figura 4.9: Sequência de Fibonacci 
Em cada etapa a (novo) $=\mathrm{b}($ anterior $)$ e $\mathrm{b}($ novo $)=\mathrm{c}$, sendo $\mathrm{c}=\mathrm{a}+\mathrm{b}$.

$$
\begin{array}{rr}
a=1 & \\
b=1 & \\
\text { 10.times dozz } & c=a+b \\
\text { play } & c \\
\text { sleep } 0.5 \\
a=b \\
b=c
\end{array}
$$

end 


\section{5 \\ Conclusão e Considerações Finais}

Neste trabalho foi proposto um alinhamento entre a matemática, programação e música, mas não para ensinar música utilizando matemática, ou o contrario, tampouco ensinar matemática utilizando programação. Tendo como foco o estimulo da curiosidade, norteado pela BNCC, no que diz respeito a inserção da computação para a educação básica, com o compromisso de desenvolver o letramento matemático, o raciocínio lógico matemático levando também em consideração o pensamento matemático e computacional.

Analisando as respostas do questionário apresentado pelos alunos, é notório um certo equilíbrio pelo interesse da disciplina matemática.

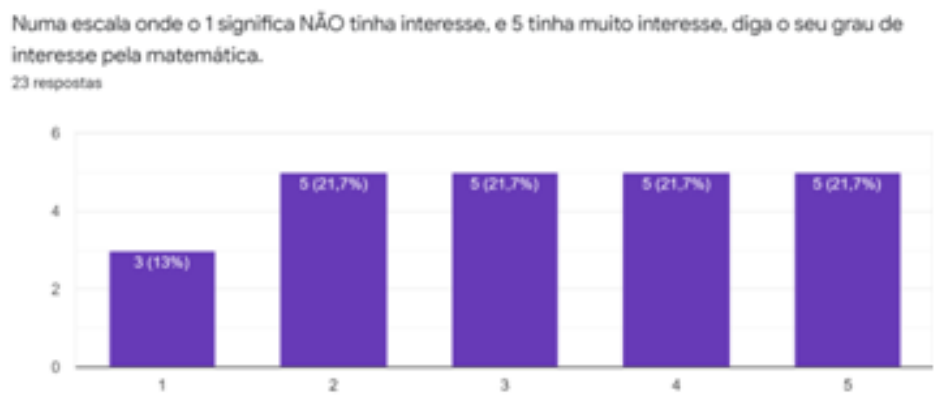

Figura 5.1:

Apesar de estar visivelmente equilibrado, muitos dos alunos não tinham interesse pela matemática. Porem com a mediana em 3, mais da metade dos alunos tinham ao menos algum interesse pela matemática. Muitos acham que a falta de interesse em aprender matemática deve-se por não conseguirem associar conceitos com as aplicações cotidianas, e o despertar da curiosidade é também um fator importante para o interesse em matemática. Um fato sobre isso é a pergunta seguinte, em que eles respondem sobre o uso de tecnologias, programação e afins. Onde eles respondem se o uso das mesmas deveria acontecer com mais frequência. 


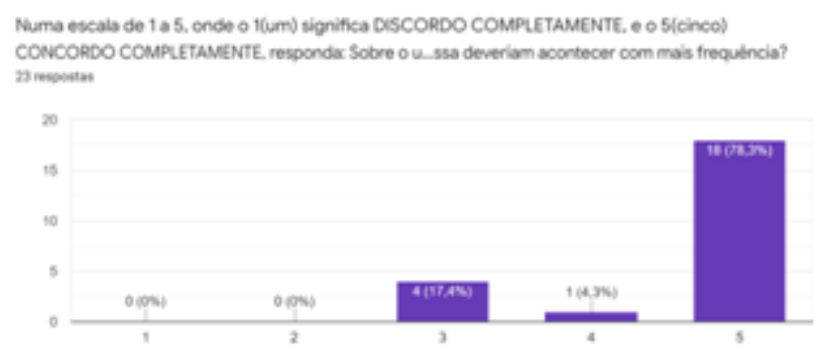

Figura 5.2:

'Mais de $70 \%$ da turma concorda completamente com o uso de tecnologias, onde chegamos mais uma vez sobre as aulas atrativas e interesse pela matemática. Um ponto interessante desse gráfico também, é que ninguém ao menos discorda completamente com o uso de tecnologias em sala de aula.

Sobre o uso do Sonic Pi no aprendizado de matemática e sobre o interesse na matemática.

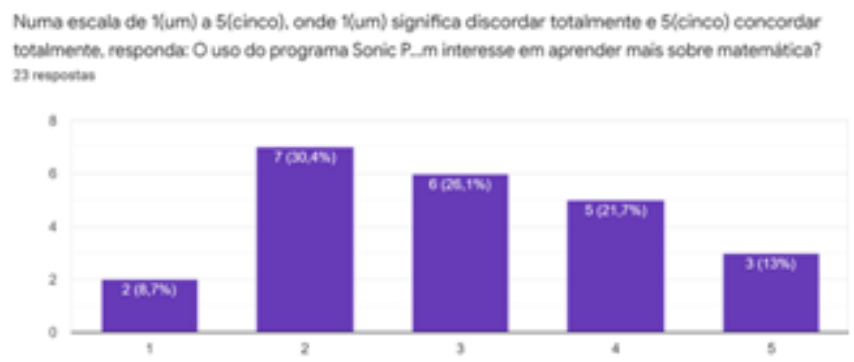

Figura 5.3:

Observou-se em relação ao uso do programa Sonic Pi, se despertou ou não algum interesse em aprender mais matemática, é possível dizer que só a utilização do Sonic Pi como ferramenta não é capaz de trazer a total atenção e curiosidade para a matemática, mas se compararmos com a figura 5.1, houve uma diminuição da barra em que discordam completamente. A partir dessa analise é imprescindível dizer que precisamos de mais atividades com uso de tecnologias. E isso será reforçado a frente analisando os próximos gráficos. 


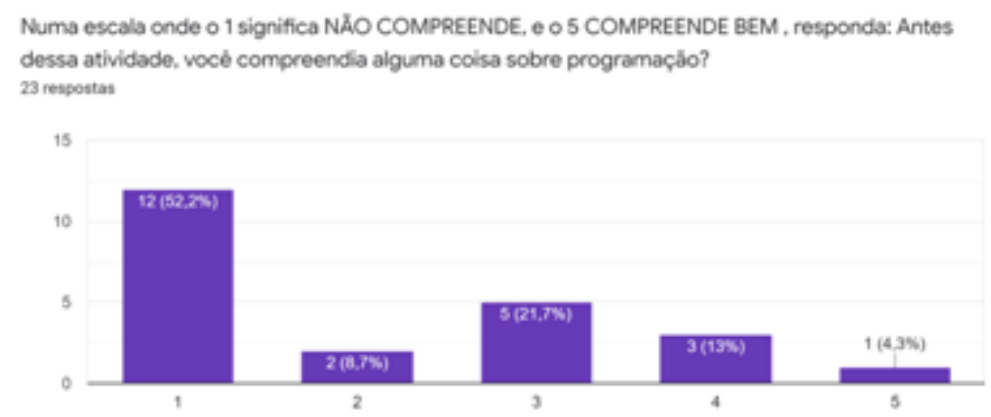

Figura 5.4:

É notório que, por ser uma escola publica de classe média baixa a baixa, e pela própria escola não fornecer atividades que envolvam programação e pensamento computacional, o conhecimento prévio sobre programação é pequeno ou quase nenhum. E atividades como essa, despertaram um grande interesse, como podemos observar no gráfico a seguir.

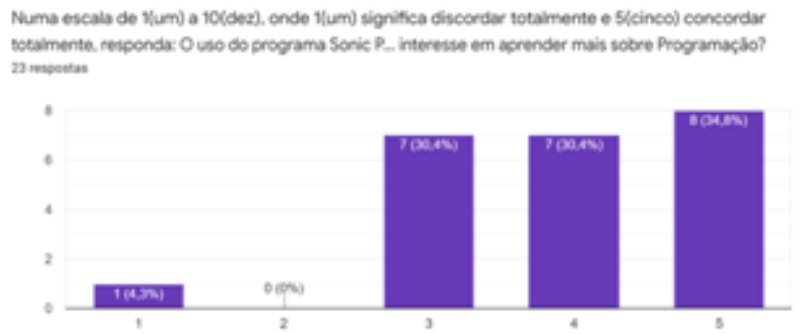

Figura 5.5:

Comparando a figura $5.4 \mathrm{com}$ a figura 5.5, no que diz respeito ao conhecimento das linguagens e curiosidade em relação a programação após a atividade, vimos a importância do processo de aprendizagem de programas, sistemas novos e atividades que atraiam a atenção. Desenvolver o pensamento computacional nessa etapa significa também atrair a atenção e despertar o interesse do aluno. Modificar e testar algo pronto, é fazer com que o aluno desenvolva a capacidade de aprender sozinho. No que diz respeito ao Sonic Pi, tivemos uma boa recepção do programa, cerca de 95\% dos alunos acharam ao menos um programa regular, cerca de $50 \%$ desses $95 \%$ avaliaram o programa como Muito Bom. Veja figura 5.6 a seguir: 


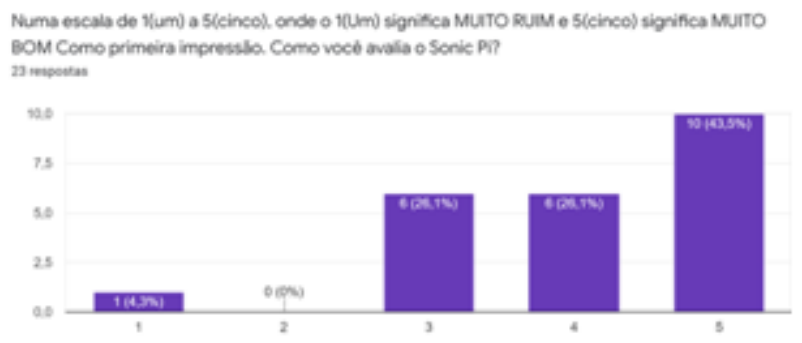

Figura 5.6:

No que tange o despertar musical pelo aluno, temos os seguintes gráficos:

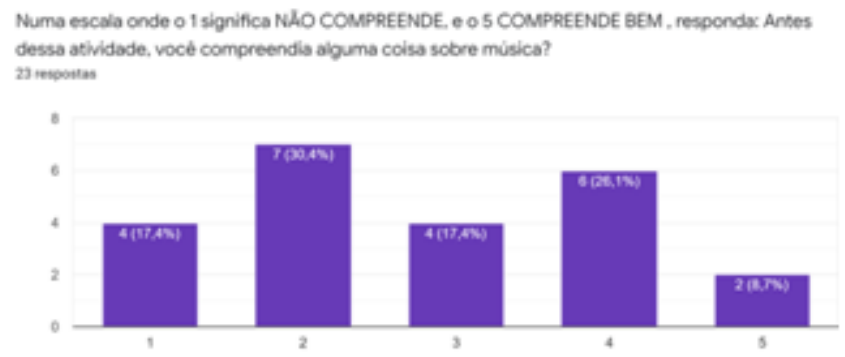

Figura 5.7:

De acordo com as respostas do questionário, alguns alunos já compreendiam algo em relação a teoria musical. Mas de acordo com o próximo gráfico há um movimento significativos de alunos que ficaram interessados em música e teoria musical.

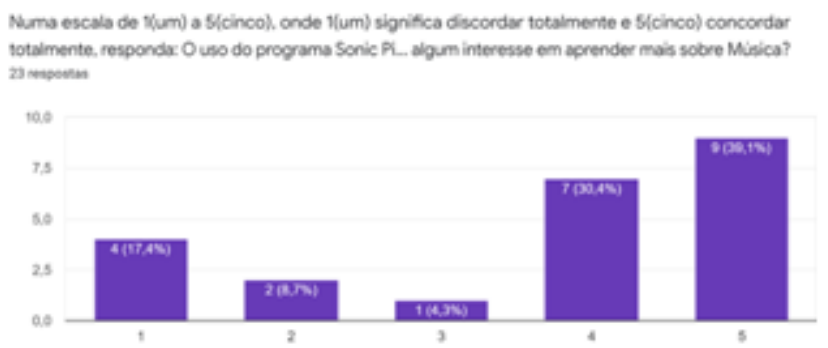

Figura 5.8:

Não menos importante, foi pedido para que os alunos avaliassem a 
atividade como um todo. Bem receptiva, é visível que a maioria dos alunos avaliou como Boa ou Muito Boa.

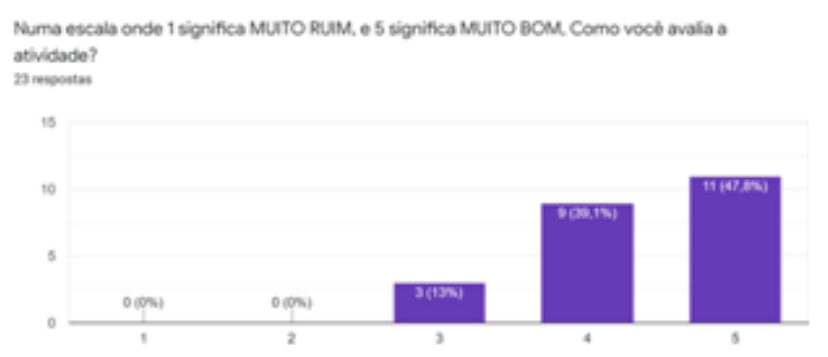

Figura 5.9:

Foi aberto um espaço para que os alunos escrevessem algum comentário. Abaixo os comentários.

- "Gostei bastante. Poderia Repetir."

- "Bem interessante...achei legal, se aprofundar mais até nos diverte."

- "Achei bacana, mas poderia ser melhor."

- "Achei legal"

- "Faz uma aula fazendo remix."

- "Muito bom, gostei muito."

- "Achei muito interessante, deveria ter mais aulas assim, me interessei mais por matemática."

- "Eu achei a atividade mais ou menos, mas fiquei interessada em saber mais sobre música."

- "Já tinha vontade de aprender antes da atividade".

- "Gostei bastante. Bem interessante."

- "Eu achei muito interessante, mas não tenho tanto interesse em saber sobre."

- "Muito boa e espero que tenham mais. primeiro porque conhece coisas nova e segundo por nunca ter feito antes."

- "Gostaria de houvesse mais aulas como essa, me despertou desejo sobre a música."

- "Tenho interesse, mas não sei muito"

- "Foi boa."

- "Achei muito interessante."

- "Sim. Eu gostei e gostaria de saber mais!! Achei interessante."

- Achei muito legal, mas não sei se seria pra mim."

- "Achei muito interessante. É uma coisa nova de aprender."

- "Eu achei a atividade muito interessante, pois aborda sobre programação, 
matemática e música. Acredito que atividades como essa estimulam o conhecimento. Eu terminei a palestra com vontade de saber mais sobre os assuntos." - "Gostei muito."

De um modo geral conseguimos atingir a proposta inicial desse trabalho. O despertar da curiosidade através da matemática, música e programação.

Confesso que fiquei extremamente feliz em realizar essa atividade, pois apesar dos desafios e problemas que ocorreram no meio do processo, e na relutância em aplicar a atividade numa escola em que sou professor, me senti completamente surpreendido com o resultado dessa ação, pois sei das dificuldades que é lecionar numa escola publica e periférica. Pretendo manter essa atividade dentro do planejamento anual em minhas aulas. Observa-se nas tecnologias e na programação que as ações permeiam na percepção, linguagem e pelo pensamento que operam na construção de conhecimento. 


\section{6 \\ Referências Bibliográficas}

AARON, Sam. Live Code whith Sonic Pi. Live Code Create Amazing Sounds On YOUR Raspberry Pi. London: The Magpi editorial. Seymour Distribution Ltda, 2015.

BLOCKLY. Disponível em: <https://blockly-demo.appspot.com/static/demos/code/index.html?lan br>

BLOCKLY GAMES. Disponível em: <https://blockly.games/>

BRACKMANN, CHRISTIAN PUHLMANN, 2017.

BRASIL. Base Nacional Comum Curricular. Ministério da Educação. 2018.

Disponível em: <http://basenacionalcomum.mec.gov.br/>

BROWN, Andrew. Music Technology and Education: Amplifying Musicality. New York: Routledge, 2015.

BURAK, Dionísio. Modelagem Matemática: ações e interações no processo de ensino-aprendizagem. Tese de Doutorado. Campinas, Unicamp.1992.

D'AMBRÓSIO, Ubiratan. Armadilha da Mesmice em Educação Matemática. Boletim de Educação Matemática, 2005.

DUVAL, Raymond. Registros de representacao semiotica e funcionamento cognitivo do pensamento. 1993 (tradução de Mericles Thadeu Moretti disponível em http://dx.doi.org/10.5007/1981-1322.2012v7n2p266 ).

DUVAL, Raymond. Comment analyser le fonctionnement représentationnel des tableaux et leur diversité. Spirale 32. 2003

EVES, H. Introdução à História da Matemática. Editora UNICAMP, 2014. 
FONSECA FILHO, Cleúzio. História da Computação: O caminho do pensamento e da tecnologia. Porto Alegre : EDIPUCRS, 2007.

MACHADO, E. Z. A. et al. Trabalhando com alunos de ensino fundamental e medio para a descoberta de talentos em computacao: um relato de experiencia. In: Workshop de Inclusao Digital Bahia-Alagoas-Sergipe, 2010, Maceio. X Escola Regional Bahia-Alagoas-Sergipe, 2010.

MARTINEAU, J. Quadrivium. São Paulo: Realizações Editora, 2014.

MED, B. Teoria da Música. Brasília: Brasília Artes Gráficas, 1996.

MERCADO, L.P.L. Formação Docente e Novas Tecnologias. IV Congresso RIBIE, Brasilia 1998.

N.Piskunov, Cálculo Diferencial e Integral, Tomo I, Editora Mir, 1977.

PASTERNAK, E. Visual Programming Pedagogies and Integrating Current Visual Programming Language Features. Dissertação (Mestrado) Robotics Institute, Carnegie Mellon University, August 2009.

SONIC PI. Disponível em: https://sonic-pi.net/tutorial.html.

SCRATCH. Disponícel em : <https://scratch.mit.edu/>

FIORELlI SILVA, I. L.; ALVES NETO, H. F. O Processo De Elaboração Da Base Nacional Comum Curricular (BNCC) No Brasil E A Sociologia (2014 a 2018). Revista Espaço do Currículo, [S. 1.], v. 13, n. 2, p. 262-283, 2020. DOI: 10.22478/ufpb.1983-1579.2020v13n2.51545. Disponível em: https://periodicos.ufpb.br/index.php/rec/article/view/51545.

WING, J. M. Computational thinking, Commun. ACM, vol. 49, no. 3, p. 33, Mar. 2016. 